\title{
A Second Order Diffusion Model with Application in Capital Flow
}

\section{A Brief Report on the Creation and the Academic Output of the Federal University of ABC}

\section{A Short Report on Role of EMBRAPA in the Brazilian Agribusiness}

\begin{abstract}
The initial project regarding the paper to be presented in the "Seminário internacional Papel do Estado no Século XXI: desafios para a gestão pública" promoted by the "Escola Nacional de Administração Pública (ENAP) e o Ministério do Planejamento, Orçamento e Gestão do Brasil (MP)", was restricted to the last two topics, that is the impact of public investment on the higher education system and on the technological advances fostering the Brazilian agribusiness. Instead of writing an overview regarding the general higher education system and the agribusiness complex we selected two emblematic enterprises proving that making the right choices public investments have a very high return rate.

However meanwhile we closed the basic concepts regarding a new theory dealing with diffusion process. This new theory introduces a second order approach to the dynamics of particles scattering in some supporting medium. The new contribution is the consideration of two simultaneous flows in the same system dividing the diffusion cloud into two fractions. The possibility to work with two simultaneous flows is much more adequate to model population dynamics, infectious diseases with people moving in and out some environment and clearly capital flux. Despite the fact that we have no expertise in economics we dare to present a first essay in
\end{abstract}


capital flux since the results obtained by the new model are quite interesting and acceptable by the common sense. We are also convinced that it is the obligation of the university to take risks and try to open new roads. The ultimate aim of a genuine research project is to present unexpected results. If in the research output there is no surprise something is missing.

Therefore we decided to make two short reports on the Federal University of $A B C$ in São Paulo, a very successful new university and on EMBRAPA which is a paradigm in the agribusiness complex, following a relatively extended presentation of the second order diffusion theory to capital flux. Besides the economic turmoil affecting Brazil and the international community as well deserves at least some alternative model that could better explain what is going on.

Our apologize for that new orientation.

Keywords: agribusiness, theory, higher education, economy, economic crisis, capital, scientific method, research method, scientific education, education, methodology, scientific research, science and technology, environment, scientist, public company, agriculture 


\section{A Second Order Diffusion Model with Application in Capital Flow}

\section{Introduction}

The extraordinary advance in computer technology in the last 30 years together with the demand for integration of several knowledge fields to solve new and challenging problems pushed forth the development of modeling techniques. Initially confined to physicochemical matters modeling was latter introduced to simulate population dynamics, environmental dynamics, epidemics and more recently diseases evolution and social behavior. Particularly the dynamics of economic systems and knowledge transfer belongs to this last theme. Not seldom the mathematical tools were taken from the models used in natural and engineering sciences and adapted to the new fields of knowledge. This type of adjustment works well for simple cases but may fail in more complex situations. Take for instance the classical diffusion equation in its original form to represent the evolution of contagious deceases or capital flow. The fundamental hypothesis of the classical diffusion theory rely on the assumption that the totality of the material contents, whatever it may be, particles, people, money, moves along a single flow trajectory in a given substratum. This is a rather restrictive hypothesis when we consider infected people moving in and out some environment or capital flow that may occur simultaneously in two opposite directions.

The difficulty is that while acknowledging the limitations of the mathematical tools the demands for new results forces the introduction of rather artificial modifications in the basic governing equation to match some experimental results and observations. The introduction of complementary sources and non-linear terms in the governing equations allows for tuning up the new parameters to match almost all possible observations. Therefore, the validation is restricted to a given circumstance but not concerning the phenomenon itself. If the model together with the parameters estimated for a given data set is applied to a similar problem but with a different input the theoretical prevision could deviate substantially from the real outcome. It is important to distinguish the validation of a particular event from the validation of the subjacent phenomenon. This observation is particularly important when dealing with social and economic modeling.

One of the purposes of this paper is to introduce a new diffusion formulation that admits the occurrence of two simultaneous fluxes of the same contents. That is, the same contents, let us say currency, may be into two different "excitation states", income or outflow, earnings or expenditures, generating two simultaneous flows. Besides, they may change states along the process. The simulation of this 
kind of phenomenon requires a new governing equation, a fourth order equation. A short presentation of the main steps to derive this new diffusion equation is given in the next section.

\section{The classical diffusion framework}

For purpose of completeness it is convenient to make a brief introduction to diffusion processes. The ordered scattering of particles in some supporting medium is called diffusion. Diffusion may happen in a physicochemical process, salt particles disperse in water;in public health problems, malaria spreading in an environment favorable for mosquito reproduction; in a social framework, knowledge transfer in a human population.

The theory associated with the diffusion process was settled in the beginning of the last century. The motivation was the spreading of gas molecules in a confined environment. That is the theory was developed to find out how the particle concentration would evolve in space and time. The basic conclusion was that the particles move from regions where the gas concentration is very high towards rarefied gas regions.

That is nature always tries to homogenize an initially uneven particle distribution provided that the system is free from external perturbations. The analytical formulation of this phenomenon assumes as fundamental hypothesis that the particles flow rate is proportional to the slope (gradient) of the concentration distribution. The direction is clearly from regions of high concentration to regions with low concentration. The modulus of the flow rate is therefore given by (Fick's law):

$\left|\boldsymbol{\Psi}_{\mathbf{1}}\right|=D\left|\frac{\partial q}{\partial x}\right|$

The parameter $D$ is the diffusion coefficient and is the modulus of the concentration distribution gradient. This parameter is related to the interaction between the resistance of the supporting medium against the particles motion and the repulsive force exerted by the particles among themselves. Figure 1 illustrates the diffusion process profiles of particles initially concentrated in a small interval with center at $\mathrm{x}=0.5$.

High values of the concentration gradient imply correspondingly high flow rates. Therefore as can be seen in the figure 1 as the process develops the flow rate decreases since the concentration distribution becomes smoother. Using the classical mass conservation principles and the flow rate law introduced above the following equation is obtained: 
$\frac{\partial q}{\partial t}=D \frac{\partial^{2} q}{\partial x^{2}}$

Figure 1: Evolution of the particle concentration distribution in time and space. For $\mathrm{t}=0$ particles are highly concentrated close to $\mathrm{x}=0.5$. Particles spread laterally as time increases

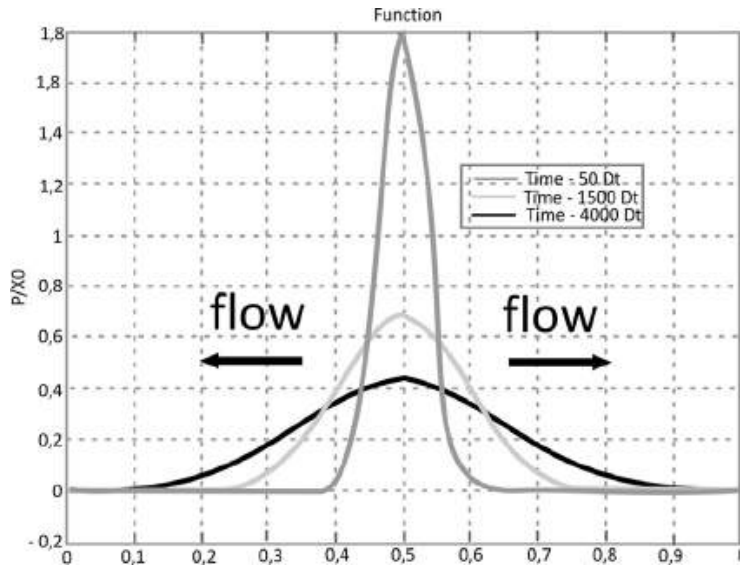

Careful experimental observation have been made for several types of particle scattering in different substrata. For regular diffusion processes equation (1) has proved to be quite satisfactory. Figure 2 shows the evolution in time and space of a regular diffusion process. The problem arises when there are non expected phenomena taking place in the process, as time delay in particle motion. In these cases the classical equation does not provide a satisfactory solution. To solve the discrepancies between experimental observation and the prediction of the classical theory some extra terms are introduced to complete equation (1).

Figure 2: Evolution of the particle concentration distribution in time and space. For $\mathrm{t}=0$ particles are highly concentrated close to $\mathrm{x}=\mathbf{0 . 5}$. Particles spread laterally as time increases

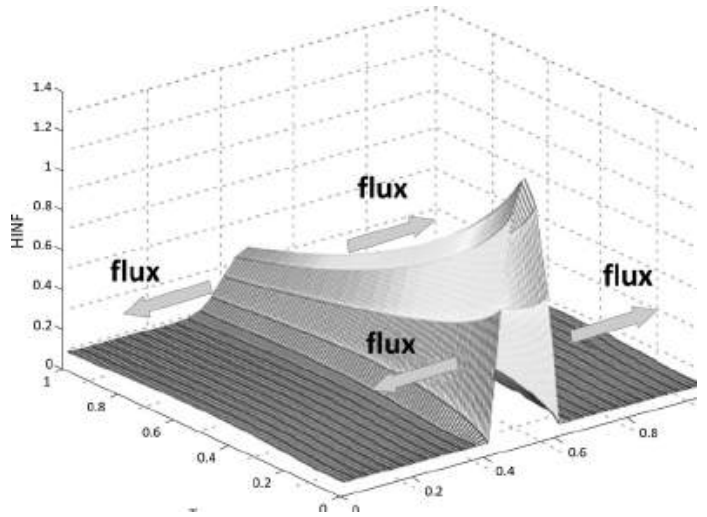


Now the hypothesis that all particles at a givencross-section of the particle cloud move with the same speed is a considerable simplification. What is physically consistent is that the flow rate given by the Fick's law:

$\boldsymbol{\Psi}_{\mathbf{1}}=-D \frac{\partial q}{\partial x} \mathbf{i}$

represents the mean value of a flux distribution with a very small deviation from the mean(fig.3a). So the diffusion equation (1) is an approximation that works out satisfactorily for very small values of $\delta$.

Figure 3: Flow rateprobabilitydensity function for single flux diffusion (a). Flow rate probability density function for bi-flux diffusion (b). $\delta$ very small
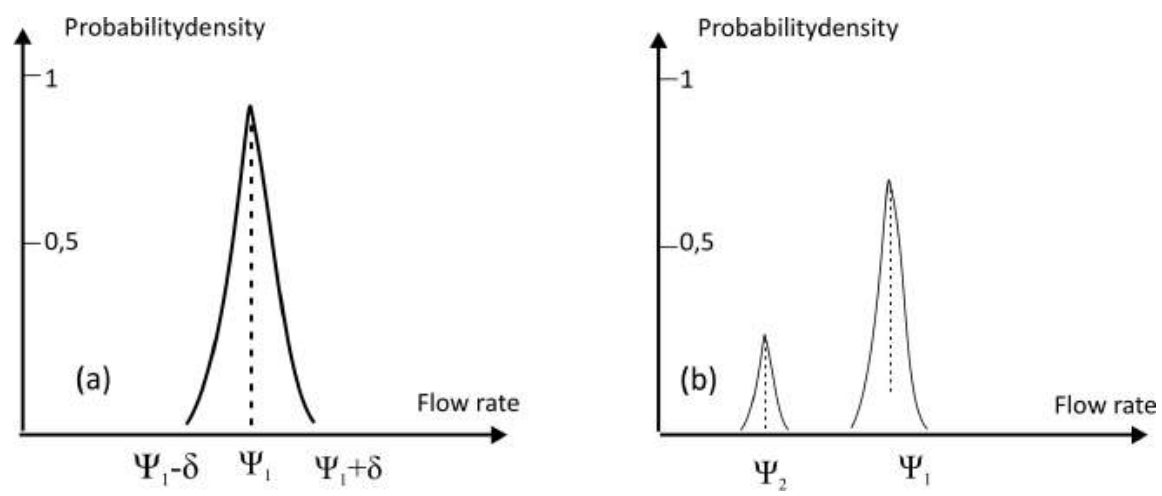

It is not impossible that in some cases the same particle system is split into two sets scattering with different flow rates (Fig. 3b). Beware we are not saying that there are two different species in the same flow, but it is the same species excited into two different energy states. If there were two different species the problem could be solved with two equations of the same order as introduced above, equation (1), with two different diffusion coefficients $D_{1}$ and $D_{2}$ and possibly with the inclusion of coupling terms. Therefore, we need a new theory that would allow splitting the particles cloud in the system into two sets of the same nature diffusing with different flow rates. That is the mass flux is divided into two fractions, excited by two distinct flow potentials generating two flow rate vectors $\boldsymbol{\Psi}_{1}$ and $\boldsymbol{\Psi}_{2}$ as shown in the figure 4 .

Figure 4: Similar particles scattering with different flow rates. Red cells correspond to $2 / 3$ and black cells to1/3 of the total mass

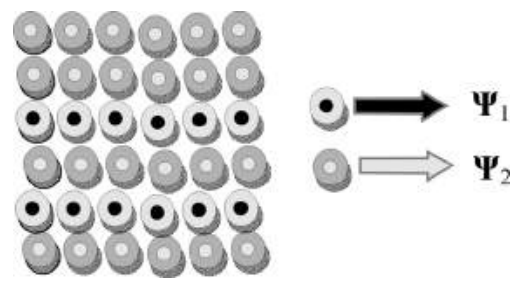


As presented in the next section if we introduce a delay on a certain fraction of the diffusing particles, say $(1-\beta)$ with $0<\beta<1$ allowing the complementary set $\beta$ to scatter according to the classical theory, the following governing equation is obtained:

$\frac{\partial q}{\partial t}=\beta D \frac{\partial^{2} q}{\partial x^{2}}-(1-\beta) \beta R \frac{\partial^{4} q}{\partial x^{4}}$

What we have now is a unique concentration distribution where the particle flux is divided into two distinct portions. Figure 5 illustrates the difference in the response of the two diffusion approaches for a mass concentration input at $t=0$ at the center of the segment $[0,1]$. The presence of a secondary flux introduces acceleration on the concentration decay while spreading the solution along the $\mathrm{x}$-axis. The behavior of the concentration for the bi-flux theory depends strongly on the parameters $\beta$ and $R$.

Figure 5: Response to a concentrated distribution at $x=0.5$. (a) Single flux diffusion process, classical solution; (b) bi-flux diffusion process, fourth order PDE
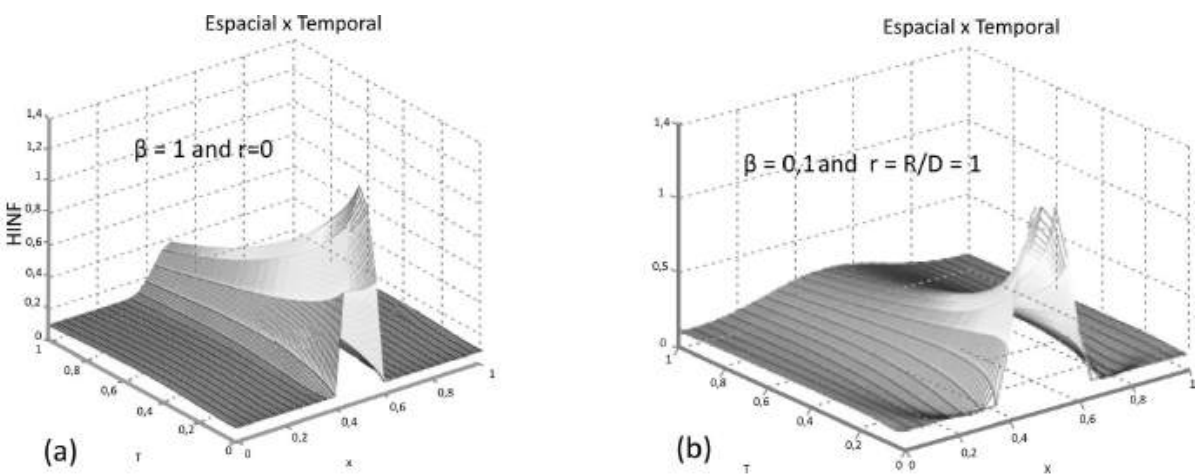

A clear example where this phenomenon is not only plausible but necessary is capital flow. Even in our small universe we all have income and expenses, that is, cash inflows and outflows. It is the same money flowing in two opposite directions possibly with different speeds. The ultimate purpose of this proposal is to show that it is worthwhile exploring the new approach introducing the bi-flux phenomenon in the context of capital flow. The behavior of the economy could be better estimated using the second order flux theory as presented here.

\section{An overview of the Second Order Theory}

The derivation of the second order theory can be obtained with a very simple discrete model. Indeed, consider a row of cells such that each cell can communicate with the neighboring ones. Let the contents of each cell be partly redistributed to the adjacent cells in equal portions and partly retained in the cell at each time step. 
Figure 6 represents the distribution process for a characteristic time step $\Delta t$. The fundamental idea is therefore, to assume that the contents of a cell $n$ at a time $t$ changes at each time interval $\Delta t$ such that a fraction $B$ is equally redistributed to the right, $n+1$, and left, $n-1$, neighboring cells while the remaining portion (1-b) stays temporarily confined in the same cell $n$. The set of equations derived with the help of the discrete approach representing this distribution law reads:

Figure 6: Contents distribution considering partial retention

$(1-\beta)$

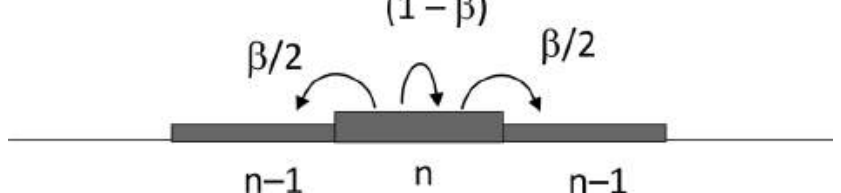

$q_{n}^{t}=(1-\beta) q_{n}^{t-1}+\frac{1}{2} \beta q_{n-1}^{t-1}+\frac{1}{2} \beta q_{n+1}^{t-1}$

$q_{n}^{t+1}=(1-\beta) q_{n}^{t}+\frac{1}{2} \beta q_{n-1}^{t}+\frac{1}{2} \beta q_{n+1}^{t}$

where $0 \leq \beta \leq 1$. Clearly with $b=1$ the above equations represent the discrete formulation scheme leading to the well-known second order classical diffusion equation. But with $\beta \neq 1$ a new equation is obtained. After the proper operations and assuming the continuity requirements for the function $q(x, t)$ we get [1] [2].

$\frac{\partial q}{\partial t}=\beta D \frac{\partial^{2} q}{\partial x^{2}}-(1-\beta) \beta R \frac{\partial^{4} q}{\partial x^{4}}$

The fourth order term with negative sign introduces the effect of retention. The coefficient $D$ is the well-known diffusion coefficient and $R$ is a new coefficient that we will call reactivity coefficient. The parameter $\beta$ is a control parameter expressing the balance between diffusion and retention when both are activated simultaneously. The retention effect reaches its maximum for $\beta=0.5$. Clearly retention cannot be activated without diffusion, that is, while diffusion can take place without retention $\beta=1$, the complementary process, that is, retention without diffusion $\beta=0$ is not possible.

It is remarkable that the discrete approach shows that non-linear terms are not required to represent temporary retention at least for the case of homogeneous isotropic media. This means, as it should be expected, that temporary retention belongs to the class of primary phenomena and, in general, is not a secondary perturbation on the diffusion process as usually assumed for modeling anomalous diffusion.

Equation (2) shows clearly the existence of two different diffusion processes. The variable $q(x, t)$ represents the mass concentration and it is not difficult to see that 
two distinct velocity potentials come into play one of them corresponding to the second order differential term and the other one corresponding to the fourth order differential term. Particles belonging to the fraction $b$ follow the classical Fick's law, it is the primary flux that will be called $\boldsymbol{\Psi}_{1}$ and particles belonging to the fraction (1- $\beta$ ) follow a new law, it is the secondary flux that will be called $\boldsymbol{\Psi}_{2}$. Considering equation (1) and anticipating the mathematical structure of the integrand for the mass conservation principle it is not difficult to see that the fluxes are given respectively by:

$\boldsymbol{\Psi}_{1}=-D \frac{\partial q(x, t)}{\partial x} \mathbf{e}_{1}$ and $\boldsymbol{\Psi}_{2}=R \beta \frac{\partial^{3} q(x, t)}{\partial x^{3}} \mathbf{e}_{1}$

The physical meaning of the primary flux is well known, namely, the particle concentration distribution tends to smooth out along the $x$-axis. The particles move from higher concentration regions toward lower concentration regions. The secondary flux is concerned with the curvature variation of the concentration distribution. It grows with the increase in the curvature. Since increasing curvature means local accumulation, the secondary flux may be interpreted as a process that opposes the growth of local concentration. It is also remarkable that the intensity of the secondary flux increases linearly with the fraction $B$ of particles belonging to the primary flux.

\section{Applying the second order theory to simulate simple cases of capital flow.}

In order to justify the presentation of this proposal it is convenient to show that some basic results match the common sense expectations for simple situations. The questions that certainly can be raised from the following examples could only be answered through a careful investigation effort organized through the convergence of different knowledge fields.

It is important to keep in mind that the present theory is intended to apply the second order or bi-flux theory to typical cases where the classical approach fails to represent the coupled flux. Capital flow is adequate to our purpose. Therefore, we will consider the economic behavior of a small social chain that is the overall response of a relatively restricted economic system.

\section{Inflow and outflow in a simple economic chain.}

Preliminary analyses have shown that the use of the bi-flux theory leads to simulations that reproduce, at least qualitatively, some of the most important economic states.

Consider the case of some economic chain in the interval $(0,1)$. The resources concentration, that we call $q(x, t)$, vary slightly from the initial point $x=0, q(0,0)=0.5$, 
to the end of the chain, $x=1, q(1,0)=0.56$ for some reference initial time $t=0$. The boundary condition at $x=0$ prescribe no flow meaning that it is the end of the chain with no interaction with external agents. At $x=1$ the agents in the chain interact with the outer environment such that the primary flow $\Psi 1$ is directed inward and a secondary flow $\Psi$ 2outward (Fig.7). The solution to this problem with the initial condition $q(x, 0)$ given below is very simple.

Figure 7: Profile of aggregated money fluxin an economic chain

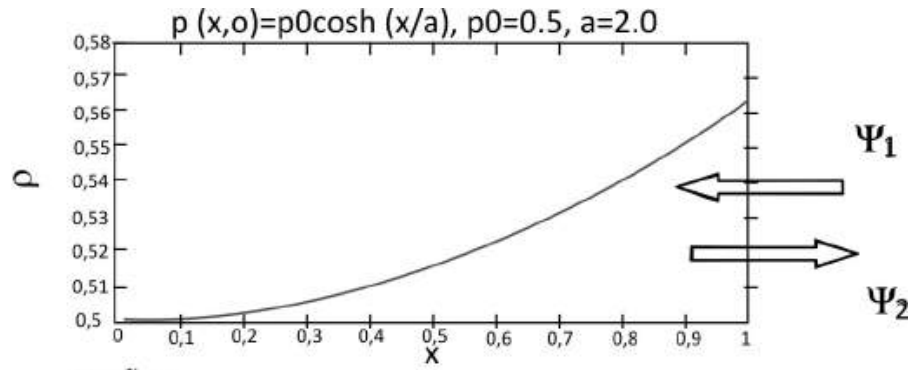

No flux

The parameter $\rho$ controls the time evolution of the diffusion process. Figure 8 shows the variation of $\rho$ with $\beta$ for some values of the parameter $r$. Clearly for $\rho>0$ the process evolves in the direction of assets accumulation ept $>1$, meaning that the volume of capital inflow exceeds the volume of capital outflow. For the opposite case, $\rho<0$ and ept $<1$ the process enters in a recession cycle accumulating losses progressively. Points combining $\beta$ and $r$ such that $\rho$ vanishes represent stagnation points that may be considered in a different context points of equilibrium. We prefer call those points stagnation points, no gains no losses.

Figure 8: Variation of the evolution control parameter $\rho$ with the mass fraction distribution $\beta$

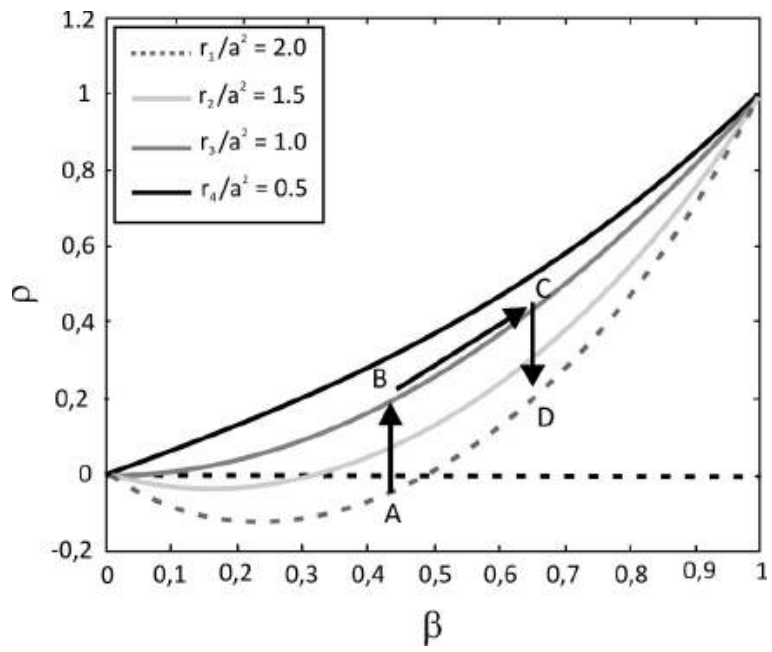


Initialcondition:

$q(x, 0)=p_{0} \cosh \left(\frac{x}{a}\right)$

Boundary conditions:

at $x=0 \quad \Psi_{1}=\Psi_{2}=0$ no flux

at $\mathrm{x}=1$

$\Psi_{2}=q_{0}\left(\frac{1}{a}\right)^{3} e^{\rho t} \sinh \left(\frac{1}{a}\right)$

$\Psi_{1}=q_{0}\left(\frac{1}{a}\right) e^{\rho t} \sinh \left(\frac{1}{a}\right)$

The solution is

$p(x, t)=q 0 \operatorname{e} \rho \cosh (x / a)$ where $\rho=\frac{D \beta}{a^{2}}\left(1-(1-\beta) \frac{r}{a^{2}}\right) \quad r=R / D$

Note that as stated before $\Psi_{1}$ corresponds to the primary flux that is, it is assumed to exist independently of $\Psi_{2}$. The subsidiary flux exists, if and only if $\Psi_{1}$ is active. This means that spending money is only possible if there is money coming in.

$D, R, \beta$ and $a$ maybe considered preliminary as defined below.

$D$ : represent the tools to encourage (discourage) investments, high values of $D$ correspond to intensification of the capital inflow rate

$R$ : represents regulations to reduce (increase) the spending time rate, low values of $R$ correspond to contention in the outflow rate that is it tends to decrease the cash outflow rate.

$\beta$ : this is a very important parameter regulating the distribution between the volume of investments and expenditures. It also controls the outflow rate, if $\beta$ is small the expenditure rate will fall in the same proportion. It means that if there is no money available payment becomes impossible.

$a$ : may be considered as the length of the connected activities composing the economic chain.

It is important to introduce now the interpretation of the space variable representing the economic chain where the several agents are distributed. Recall that the first order driving force of any diffusion process is the difference between 
the concentrations in two neighboring points of the economic string. Following this rule we will divide the economic chain into three segments. $E_{1}$ consisting of the economically dominant agents, in the following examples this group is closer to the external environment, $x=1 . E_{3}$ consists of the economically weaker sector, close to $\mathrm{x}=0$, and $\mathrm{E}_{2}$ composed by agents with intermediate impact on the economy.

Just to give an example, suppose a certain economy following a contracting trajectory, that is $\rho<0$ as represented by point $A, r=r_{1}$, in the figure 8 . Suppose that it is required by the economic authority that the ratio (capital inflow)/(capital outflow) remain constant that is $\beta$ must be kept constant until the economy shows a positive evolution. This would be possible by reducing the value of $r=R / D$. If $D$ is kept constant because presumably it depends more on fixed external factors the solution would be reducing $R$, that is, try to negotiate extension of payment terms. This would lead to a point B with $r=r_{3}$. At this position the economy presents concrete signs of expansion and then it would be possible to attract new capital, that is, increase the value of $\beta$ to reach the point $C$. Now if it is convenient to increase $R$ and accelerate the outflow for some reason it would be possible to return to $r_{1}$ and still keep the economy in a growing track, point D.

\section{The influence of sources and sinks.}

If there are sources and sinks the diffusion equation must be modified in order to incorporate these new factors. Consider a source proportional to the concentration fraction (1- $\beta$ ) which corresponds to the capital outflow and a sink proportional to the fraction $\beta$ which corresponds to the capital inflow. The sources or sinks are not originated from business as usual but require some external agency that lend or borrow money in order to improve the economic output (sources) or to spare money for future applications (sinks). The new equationreads:

$$
\frac{\partial q}{\partial t}=\beta D \frac{\partial^{2} q}{\partial x^{2}}-\beta(1-\beta) R \frac{\partial^{4} q}{\partial x^{4}}+A(1-\beta) q-C \beta q
$$

The constants $A$ and $C$ define the intensity of the source and the sink respectively. With the same initial and boundary conditions as before we get $\rho=\rho(D, R, a, \beta, A, C)$. With $r=R a^{2} / D, \alpha=A / D a^{2}, \gamma=C / D a^{2}$ we obtain the qualitative results as shown in the figures $9,10,11$ and 12 . Figure 9 shows the effect of the inclusion of a source, $\alpha>0$ and $\gamma=0$. The theory suggests that there is a critical value of $r$ that overturns the behavior from growth into loss. Therefore injection of capital only turns out to be favorable if the capital 
Figure 9: Influence of the parameter $r$ on the evolution of an economic chain for a given source $\alpha=2.0 . \quad r_{1}=10, r_{2}=5.8, r_{3}=3.5$

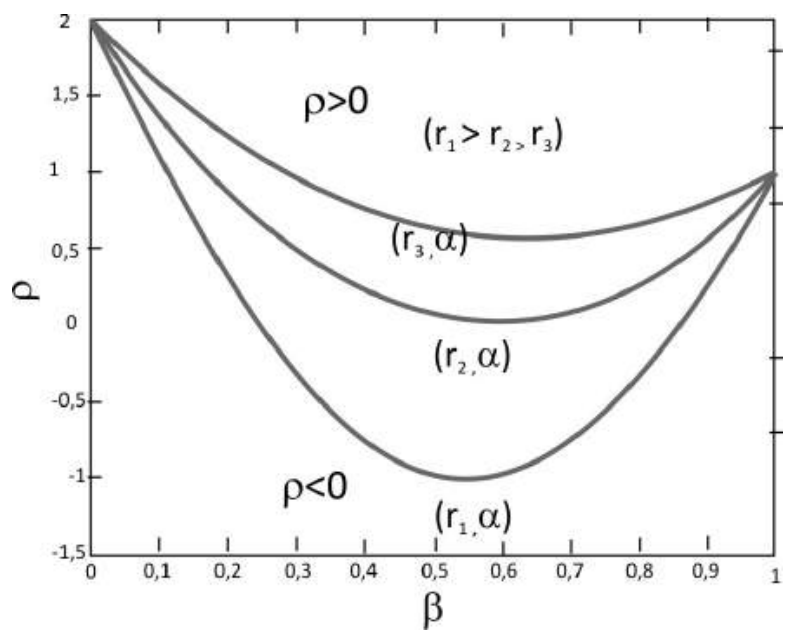

outflow is relatively low. For high values of $r$ the economy will be severely damaged. It is also interesting to notice that the action of the external source for $\alpha>1$ is more effective when outflow concentration prevails over the inflow concentration, $\beta$ relatively small. This means that injecting money in the economy is more effective if the economic activity is stimulated and people are spending moneyand taking loans.

Now if $r$ is taken constant and the source intensity $\alpha$ is allowed to vary there are two typical cases. First if $\alpha>1+r a^{2}$, figure $10-a$, it is possible to have expressive growth in the economy provided that the source intensity is high enough $\alpha>1$. For very high source intensity the more expressive growth is observed for low values of $\beta$. This scenario can be associate with a reduced outflow rate or credit expansion with more flexible rules. If the injection of money is modest it will cause more harm than benefits. For weak sources the economy will grow faster for high values of $\beta$, that is high inflow rates.

Now it is interesting to observe that for very modest sources $\alpha<1+r a^{2}$ there will always be growth although at very low increasing rate (Fig. 10-b). For this situation the best option is to stimulate capital inflow.

Now if we consider only a sink in the system, $\alpha=0$ and $\gamma>0$, that is we want to spare some money from an expanding economy the situation is much more critical. First for very large values of $\gamma$ the economy will accumulate considerable losses. The whole system will enter a descendent trajectory. For modest capital subtraction from the system, that is $\gamma$ small, it would be possible to preserve the growing process provided that $r$ is small and the capital inflow keeps $\beta$ sufficiently high as shown in 
the figure 11. Subtraction of money from the economy inhibits the outflow that is spending money and taking loans.

Figure 10: Influence of the source intensity on the evolution of an economic chain for (a) $r=4 ; \alpha_{1}=5, \alpha_{2}=2, \alpha_{3}=1, \alpha_{4}=0.1 ;$ (b) $r=0.8 ; \alpha_{1}=0.8, \alpha_{2}=0.5, \alpha_{3}=0.3$. For this case $\alpha_{i}<1+r=1.8$ for all $i=1,2,3$
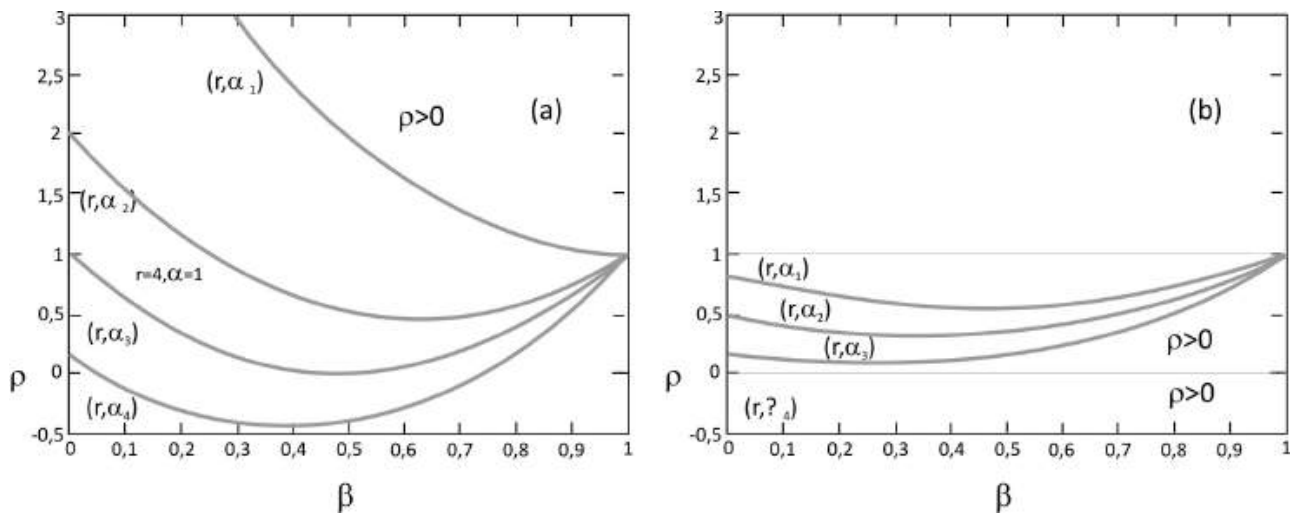

Figure 11: Influence of the parameter $r$ on the evolution of an economic chain for a given sink $\gamma=0.1 ; r_{1}=10, r_{2}=5.8, r_{3}=1.5$

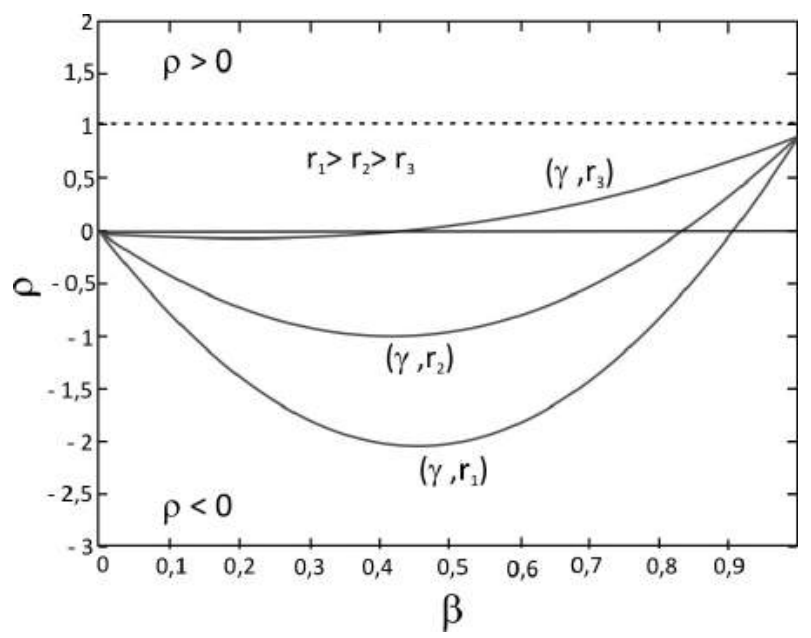

Now if we take a fixed value for $r=2$, the outcome is very critical. For very high extraction of resources from the economic system there will be degradation for all $\beta$. If the amount of assets subtracted from the system is modest only the regions where the influx prevails that is high values of $\beta$ will be associated with growth (Fig. 12) 
Figure 12: Influence of the parameter $\gamma$ on the evolution of an economic chain for a given $r=2 ; \gamma 1=2.5, \gamma 2=1.5, \gamma 3=0.7, \gamma 4=0.15$

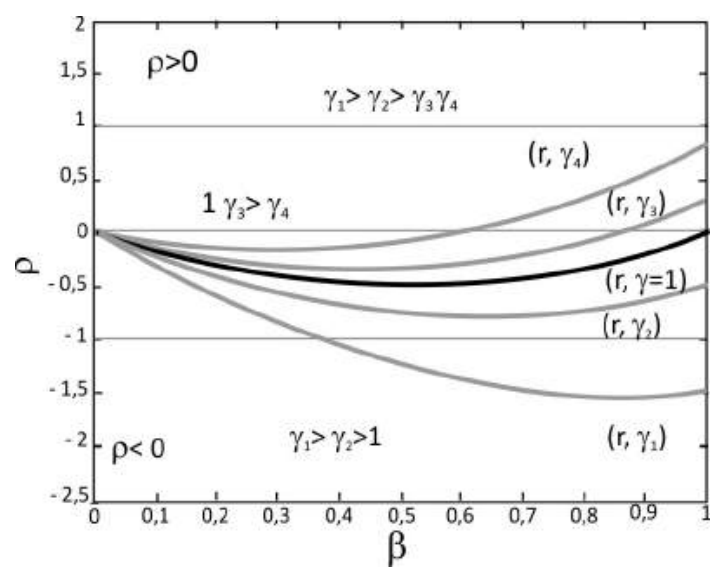

Although the interpretation of the variables advanced here may be subjected to strong criticisms, particularly the meaning of the $x$ variable indentified with the structure of the economic chain, the overall response of the model may be identified with real cases observed in the several occasions of strong economic changes.

The results derived from the bi-flux approach are plausible and do not oppose the common sense. The above examples are encouraging. Therefore, it is worthwhile increasing research efforts to obtain an accurate interpretation of the different parameters and select appropriate data to validate the model.

\section{Anomalies introduced by the boundary conditions}

Different boundary conditions introduce considerable discrepancies on the capital concentration function $p(x, t)$ for small values of $t$. We show this behavior by using slightly different boundary conditions with the same initial condition. Consider that at $x=0$ there is no flux and at $x=1$ the flux bifurcates into two sections, inflow and outflow. The initial condition is $p(x, 0)=p_{0} \cosh \left(\frac{x}{a}\right)$ and the boundary
conditions are:

(a) For time independent conditions:

$$
\Psi_{2}=p_{0}\left(\frac{1}{a}\right)^{3} \sinh \left(\frac{1}{a}\right) \quad \Psi_{1}=p_{0}\left(\frac{1}{a}\right) \sinh \left(\frac{1}{a}\right)
$$

(b) For time dependent conditions:

$$
\Psi_{2}=p_{0}\left(\frac{1}{a}\right)^{3} e^{\rho t} \sinh \left(\frac{1}{a}\right) \quad \Psi_{1}=p_{0}\left(\frac{1}{a}\right) e^{\rho t} \sinh \left(\frac{1}{a}\right)
$$


Figure 13-a shows the capital concentration variation for three different times. Clearly at the very begin $t=50 \mathrm{Dt}$ the boundary conditions $(\mathrm{a})$ induce a slight decrease in the capital concentration at the lower end of the economic chain and high concentration increase in the region close to $x=1$, where the in-and outflow are under control. Let us recall that the space variable $x$ represents the economic chain, starting with the weaker economic agents $\mathrm{E}_{3}, x$ close to zero and ending at $x=1 \mathrm{E}_{1}$ representing economic segment with more decisive power. As shown in the figure 13-a except for the higher sections of the social or economic chain, there will be losses for the segment $E_{3}$ and very low economic growth for most of the agents in the segment $E_{2}$ just after the process starts. As time increases the economy enters a growing phase for all the sections of the chain.

Figure 13: Concentration distribution for 50Dt, 1500Dt and 4000Dt for time dependent (a) and time independent (b) time dependent boundary conditions

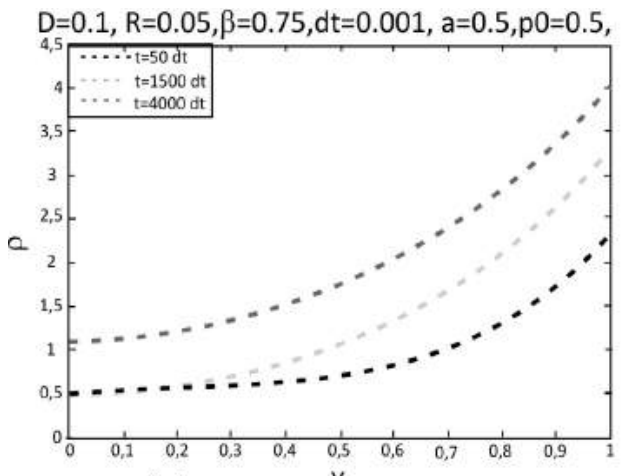

(a)

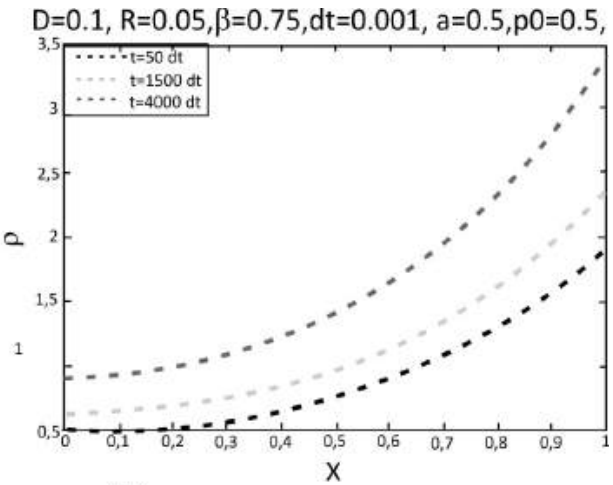

(b)

Figure 14: Concentration deviation from the initial conditions at $x=0$ as function of time, (a) fixed boundary condition, (b) time dependent boundary conditions

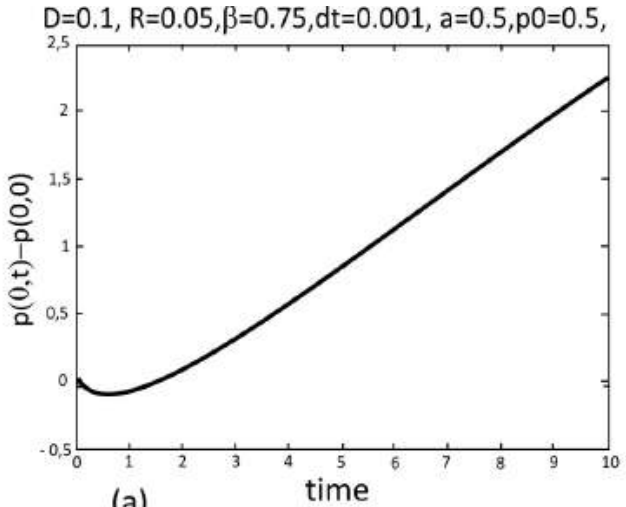

(a)

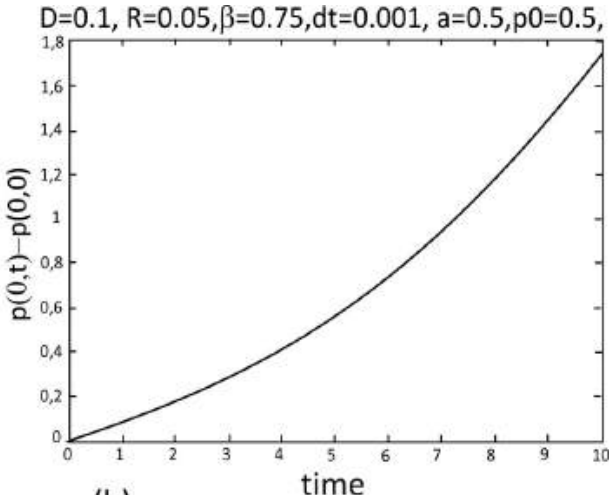

(b) 
Therefore the fixed boundary conditions trigger a wrong signalization for the economic evolution if we consider the tendency shown by the initial steps. As shown in the figure $14-a$ the capital concentration at $x=0$ decreases initially before start growing. This situation could generate panic and social disruption.

Now, for time dependent boundary conditions, that is, if the in- and out flow at $x=1$ follow the evolution tendency signalized by the whole process, all sections of the social chain will benefit from the economic growth as shown in the figure 13-b with no drawback for any section of the social chain, even at $x=0$ as shown in the figure 14-b.

Figure 15: Evolution of the first derivative of $q(x, t)$ for fixed boundary conditions (a) and time dependente boundary conditions(b)

$D=0.1, R=0.05, \beta=0.75, d t=0.001, a=0.5, p 0=0.5$,

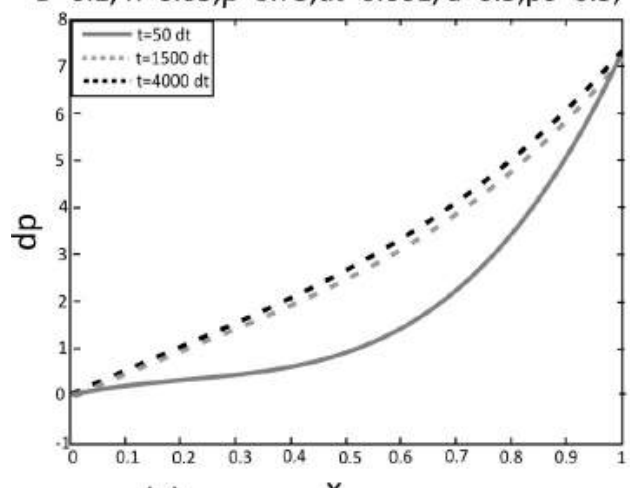

(a)
$D=0.1, R=0.05, \beta=0.75, d t=0.001, a=0.5, p 0=0.5$,

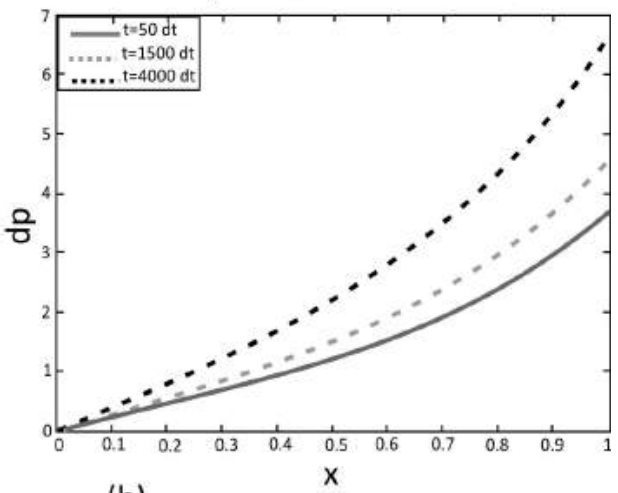

(b)

Figure 16: Evolution of the third derivative of $q(x, t)$ for fixed boundary conditions (a) and time dependente boundary conditions(b)

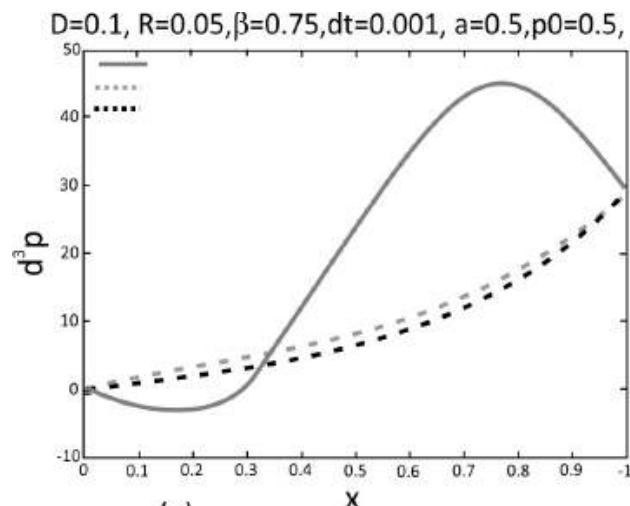

(a)

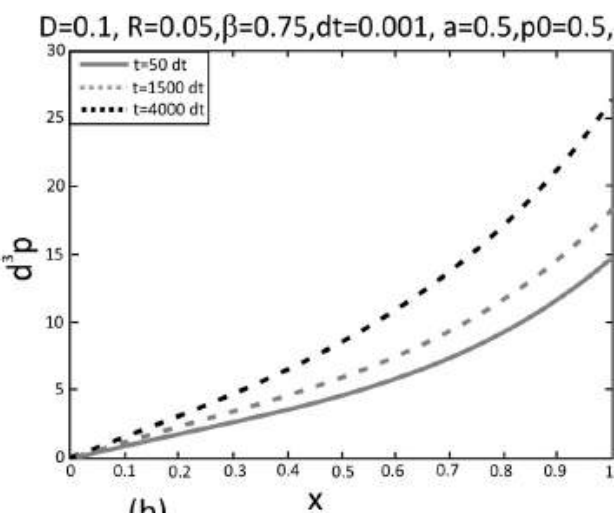

(b)

The case of time dependent boundary conditions therefore follows a very regular time evolution as shown in the figures $13-b$ and $14-b$. The first and third derivatives also are monotonic increasing function of $x$ as expected. Recall that the 
absolute value of the primary flux $\boldsymbol{\Psi} \mathbf{1}$ is proportional to $|\mathrm{dq} / \mathrm{dx}|$ and the absolute value of the secondary flux $\boldsymbol{\Psi} \mathbf{2}$ is proportional to $|\mathrm{d} 3 \mathrm{q} / \mathrm{d} \times 3|$. Therefore for the case of time dependent boundary conditions the flow rates $\boldsymbol{\Psi} \mathbf{1}$ and $\boldsymbol{\Psi} \mathbf{2}$ are well behaved monotonic increasingfunctions as shown in the figures $15-b$ and $16-b$.

Now the fixed boundary conditions, that is, time independent boundary conditions induce a peculiar behavior that could hardly be anticipate at the very beginning of the diffusion process. The dynamics of the process is particularly intense for $x>0.5$ that presumably corresponds to the agents with relatively high influence in the economic development. The inflow $\boldsymbol{\Psi} \mathbf{1}$ intensity and particularly the outflow $\boldsymbol{\Psi} \mathbf{2}$ intensity are both very high in this section of the chain. We believe that this parameter is difficult to be directly measured, except for the generalized "sensation" of accelerated capital gains and losses, but with modest impact on the economic growth if any.

The outflow under the conditions imposed in the diffusion process is so high for $x>0.5$ that, in order to keep the segment $E_{3}$ still alive, that is with reduced but still positive resources, there is an inversion in the direction of the subsidiary flow at $x \approx 0.3$ (Fig. 16- a). Therefore for $0<x<0.3$, both fluxes, primary and secondary have the same direction. It is a kind of loan coming from the middle segment $E_{2}$ toward the lower segment $\mathrm{E}_{3}$ in the economic scale.

After the impact at the beginning of the deflagration of the economic dynamics the process reaches the expected behavior with a smooth and monotonic increasing behavior as function of $x$. Despite the fact that this is only a very elementary model the qualitative divergence in the growth process for the two alternatives presented here are not incompatible with real cases reports. The model suggests that, if the in- and outflow conditions for the economic segment $E_{1}$, with the responsibility of negotiating with external agents - boundary conditions - do not allow for a flexible evolution in time to match the internal demands determined by the natural evolution path, at least in the very beginning, there will be unavoidable uneven economic growth distribution along the chain. Also, the initial signs do not match the forecast concerning the future economic behavior which presumably is much more positive and optimistic.

The ideas advanced here concerning the socio-economic significance of the new variables need to be carefully discussed. What we intended to show is that the new parameters introduced with the bi-flux theory allow for a much more flexible interpretation of the economic dynamics. The intensity of the secondary flow $\boldsymbol{\Psi}_{2}$ for instance is proportional to the inverse of the radius of curvature of the wealth distribution. This means that the secondary flow is directed towards regions with high wealth concentration. This is not an unusual situation. 


\section{The next steps toward the validation of the theory.}

It was shown that the classical theory, which is very useful for simulating simple diffusion processes, is not enough elaborated to deal with more complex processes. The introduction of the second order linear theory, fourth order partial differential equation, allowing for two simultaneous flows within the same diffusion process is adequate to model bi-flux processes as capital flow. This was shown in the preceding section through three particular simulations. The results indicated by the new theory, despite being primarily qualitative, very much agree with the common sense. Therefore we may advance the following statements:

1. The theory is adequate to deal with simultaneous fluxes within a same process.

2. The responses do not contradicts the observed and expected outcome.

In other words the results are encouraging and suggests an elaborated version of the model. We consider that future work should look into the following aspects:

Development of the capital flow model. The questions raised by the previous examples could only be answered through a deeper analysis of the significance of the coefficients $D, R, \beta$ and $a$. Therefore it is necessary to select some cases, initially simple cases, to be reviewed under the light of the fourth order theory. Particular attention should be given to the following items:

1.1. Establish a methodology to associate concrete economic data basis with the variables and coefficients introduced in the theory.

1.2. Selection of some cases with reliable data, available and free to be used to test the model.

1.3. Perform a detailed analysis with $b$ as function of time and examine the influence on the answers given by the solution of the equation.

1.4. A key question is to investigate the possibility of the resistivity $R$ to be a function of $\beta$. If there is strong evidence supporting this hypothesis the behavior of the solution could be substantially modified to match real cases of economic evolution.

1.5. Explore the significance of sources and sinks, probably associated with loans and debts.

Mathematical analysis. Given that it is crucial to investigate the behavior of the fundamental equation with the parameters $R, D$ and $\beta$ as functions of $x$ and $t$ it is inevitable to devote part of the attention to mathematics. Also the addition of sinks and sources and the respective influence on the response is essential. Therefore we envisage the following topics to be considered: 
2.1. Development of numerical methods for nonlinear equations of the form:

$$
\frac{\partial q}{\partial t}=\frac{\partial}{\partial x}\left(\beta(x, t) D(x, t) \frac{\partial q}{\partial x}\right)-\frac{\partial}{\partial x}\left(\beta(x, t)(1-\beta(x, t)) R(x, t) \frac{\partial^{3} q}{\partial x^{3}}\right)+\sum A_{i}(x, t) f_{i}(\beta)
$$

2.2. Analysis of the behavior of the linear fourth order equation with $\beta=\beta(t)$, function of time. Particular attention should be given to the term $\beta(t)(1-\beta(t))$ that for some particular conditions could lead to chaotic behavior.

2.3. Analysis of the stability conditions of the solution for $D$ and $R$ functions of $x$. Anisotropic media. Influence of sinks and sources on the stability of the solutions.

2.4. Behavior of particular cases with $R=R(\beta)$ as suggested by the input from the research line 2 above.

2.5. Advanced elaboration of the inverse problem for the fourth order partial differential equation [4] [5].

2.6. If it is possible to associate capital inflow and outflow with two distinct "energy states" a new notion of "entropy" could be introduced in the economy dynamics.

Finally we would like to say that a country cannot remain captive of economic models and indicators that might not represent the dynamics of the real economy. At least some effort should be done to investigate more adequate models that would allow for more efficient economic policies. There are no unique solutions, particularly in socio-economic matters. This is the intention of the present paper.

\section{References}

We have restricted the references to those dealing directly with the subject of the proposal. Although there is a huge number of papers dealing with diffusion the case of bi-flux for a single particle species could not be found. There are of course several cases where fourth order equations come into play but in different contexts or dealing with non-linear diffusion approaches. References [1] and [2] below contain several citations on classical and anomalous diffusion processes. A representative example of modeling economic behavior with the help of the classical diffusion approach may be found in the famous Black \&Sholes paper [6]. Certainly several scholars strongly criticizes the Black and Sholes theory while raising doubts about the efficacy of mathematical models in social sciences. This attitude however should not avoid a continuing effort to develop tools helping decision makers to accomplish their rules in society. The key point is not to use models as an infallible tool to take decisions. 
[1] L.BevilacquA., A.C.N.R Galeão, F.P.CostA, An. Acad. Bras. Ciênc.,A new analytical formulation of retention effects on particle diffusion processes, 83 (4) (2011) 1443-1464.

[2] L.BeVILACQUA.,A.C.N.R.GaleÃO. J.G.SimAS, A.P.R.DoCE, A new theory for anomalous diffusion with a bimodal flux distribution, J Braz. Soc. Mech. Sci. Eng. 35 (2013) 431-440.

[3] BLACK, Fischer; Myron Scholes. The Pricing of Options and Corporate Liabilities, Journal of Political Economy 81(3): (1973) 637-654.

[4] Silva, L. G., Knupp, D. C., Bevilacqua, L., Galeão, A. C. N. R. e Silva Neto, A. J., Formulação e Solução de um Problema Inverso de DifusãoAnômala com Técnicas Estocásticas, Ciência e Natura. Artigo Aceito para Publicação, 2014.

[5] Silva, L. G., Knupp, D. C., Bevilacqua, L., Galeão, A. C. N. R., Simas, J. G., VASCONCEllos, J. F. V. e Silva Neto, A. J., Investigation of a New Model for Anomalous Diffusion Phenomena by Means of na Inverse Analysis, Proc. 4th Inverse Problems, Design and Optimization Symposium (IPDO-2013), Albi, França, 2013.

[6] BLACK AND SCHOLES, The Pricing of Options and Corporate Liabilities, JournalofPoliticalEconomy, 81(3), 637-654, 1973. 


\section{A Brief Report on the Creation and the Academic Output of the Federal University of $A B C$}

\section{The new cultural environment}

In the last 70 years the world was subjected to amazing changes encompassing the whole spectrum of human knowledge and our way of life. Among several issues we may consider:

1. Global climate changes and the environment

2. Science and Technology boom

3. Socio-political and economic issues

4. The open road to the Universe

5. Cultural differences and conflicts

6. What is life? How does our brain works? Who are we ?

7. Religion, myths and beliefs

8. A small world- IT

9. The planet earth and self-destruction?

10. Art, artist and mass culture industry

11. Rational and transcended knowledge

All these points are essentials to propose the identity of a university for the XXI century. Particularly the extraordinary progress in science and technology was made possible due to two main factors: advancement in observation: macroand microcosms and advancement in computer technology and applications. An immediate consequence of these two factors together with the new challenges imposed by the needs of our society was the convergence of disciplines formerly isolated by strong barriers. The disciplinary convergence has strong impact in the university academic structure. It is necessary to consider, besides reshaping the scientific guidelines, the emerging of new technologies in all fields and the new professions and new options of higher education.

All these new initiatives are coming up very quickly. Then I would say that more than the knowledge era we are living an era of cultural shock. In addition, in times of cultural shock we need to change considerably our attitude towards education. The committee in charge of designing the UFABC project was well aware of these new conditions and the difficulties inherent to the creation of a University that would challenge the traditional academic structure. In any case one important obstacle was not present, namely the academic committees, the faculty senate and all the 
organized groups that are the guardian of the traditional academic structure. The University would be created from scratch. The obstacles would come from outside. These are not so dangerous as the internal destructive forces.

\section{The basic principles}

So the Federal University of the $A B C$ was planned considering the conditions imposed by the new cultural environment. The following basic principles were taken as essentials:

1. The traditional university organization is hopeless

2. There is no much time to think and take decisions

3. It is necessary to undertake risks

4. It is necessary to be prepared to make quick changes in orientation

5. It is necessary to challenge traditional rules and fight for new and more flexible statutes adequate to the present times

6. It is necessary to find a suitable "board" to rise above the cultural "shock wave"

7. Anyway it is necessary to be prepared to fall down and get to your feet again

Keeping in mind those challenges the committee started working on the basic academic principles, the cornerstones on which the new University would rest. Although not explicitly appearing in the texts of the implementation committees the academic structure of UFABC was supported by four very basic principles:

\section{Learn rather than Teach}

Against the teaching strategies prevailing in the Brazilian culture, it was acknowledged that the University must be a place intended primary to learn rather than teach. This may be apparently easy to implement but it is not. The primary attitude towards the students is that they would learn only what the teacher teaches. The student is considered a passive player in the learning process. The concrete expression of the new attitude was the limitation of number of class-hours per week. It was strongly recommended no more than 15 class-hours per week, 12 being the desirable charge. The students were encouraged to study by themselves and to look for the solutions of new problems autonomously. The education was centered on the following principles:

Fostering creativity - More individual work and less classes - Think.

Building self-confidence - To dare and to reduce aversion to risk.

Learning to take decisions and to stimulate entrepreneurship - Less complaints and more solutions. 
Together with this new attitude, it was strongly recommended that the sharp boundaries separating the university community into very specific layers (professors, students, technicians, administrators) should be dissolved. It is crucial to build up a new academic community.

\section{Do not pour new wine in old bottles}

Interdisciplinary research has come to stay. It is already a successful approach to tackle complex problems. However courses, particularly undergraduate courses follow the classical organization. Departments remain as the fundamental academic units in the university structure. This kind of contradiction confuses the students. It is necessary to break up the departmental structure. Together with breaking down the departmental barriers a reshuffle of the main themes distributed among the classical disciplines, physics, chemist, mathematics, biology, computation should be done. New guidelines more adequate to the new science and new technology should be implemented substituting the old ones. The committee proposed that the new university should be organized with three schools, namely: Natural Sciences and Humanities, Mathematics, Computation and Cognition, Engineering and Social Sciences. The new guidelines would be: Structure of Matter, Energy, Transformation Processes, Communication and Information, Representation and Simulation (Mathematics), Humanities and Social Sciences. The student should have more freedom to select courses and professional options keeping credit requirements for basic courses at a minimum level.

\section{First discover then publish}

Advancement of knowledge rather than thickening the authors' CV should be the focus of publications. The contribution of a scientist is not measured by volume but by the scientific value of the new ideas. The pressure for quantity instead of appreciation for quality delay the advancement of science and technology. Also this fundamental idea should support the performance evaluation in the academic career.

Finally the UFABC ultimate declaration of identity was settled as follows

The main commitment of the UFABC toward society is to recover the appreciation for scientific learning, to show the beauty inherent in the mysteries of nature and hidden in a mathematical object. It was founded on the assumption that knowledge is not only a means to response to market demands but above all to the enlightenment of the human spirit.

The project of UFABC is sustained by the freedom to explore new paths that will lead the University closer to its original and universal purpose: to discover, to invent and to think critically. The education system, more than ever, should encourage students to make their own choices, to take risks, to accept challenges and to think creatively. 
The UFABC is committed to the above principles that will guide the university to accomplish its mission contributing effectively for the educational enhancement of our Nation.

\section{The implementation}

The UFABC was founded according to the above principles. The first five years were difficult partly due to the resistance to accept a new education project. Our society is acquainted to follow well established educational paths. Any deviation rises suspicious attitudes most of the time assuming that education would deteriorate if the students would be free to make their own choices. High school teachers, parents and also most of the academic community did not approve the new educational project. The high school students were discouraged to apply for the new university. The local unions and community associations criticized strongly the new project. Newspapers independently from their ideological option opposed the basic educational principles and the orientation proposed by the university for the new professional careers.

So the first five years were very difficult for the faculty and the UFABC leaders. Fortunately the young professors joining the university were highly qualified and committed with the project. Graduate courses started simultaneously with undergraduate courses so that the professors joining the university could continue their research work. Collaborative agreement, frequently very informal, were established with other universities allowing for the continuation of research projects of the new faculty joining the university.

Figure 1: UFABC scientific production, quality of journals versus impact, SIR GLOBAL 2013, SCIMA GO LAB

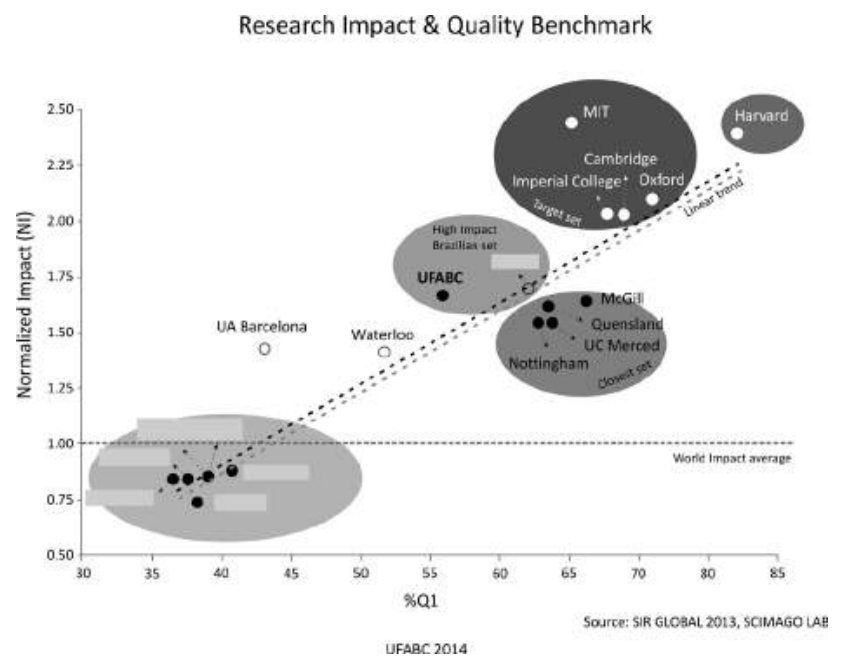


After 10 years the UFABC is now showing that the effort was worthwhile. The academic output of the university is being recognized internationally as shown in the figure 1. It is the best Brazilian university considering the criteria of high-quality publications, normalized impact fator, overall excellence and internationalization. Certainly the volume of publication is still less than other older Brazilian universities.

According to the Ministry of Education evaluation process, the UFABC is distinguished as one of the 20th best universities in Brazil among 2000. The UFABC belongs to the select group with the highest possible score. In 2013 this recently founded University conquered the first place in the education performance for the bachelor courses: Chemistry and Mathematics and the engineering courses: Material Science and Engineering and Environmental Engineering.

The former UFABC student Thiago Alencar who obtained the undergraduate degree in Aerospace Engineering in 2011, was honored with the "The Theodore W. Hissey Award" sponsored by the IEEE. It was the second Brazilian to receive this prize. He wrote a letter to the UFABC faculty finishing with the following words:

"I would like to dedicate this prize to the (UFABC) professors and share my achievements accomplished in last few years expressing my high appreciation for the Bachelor degree project that I finished and has made a big difference not only my academic life but also in my education as a citizen, besides the several opportunities that this pioneering and audacious academic project has opened in my life. I owe a great deal for being what I am now to my former professors who even facing so many difficulties believed in the interdisciplinary pedagogical proposal of the Bachelor program and that fight constantly to keep the university mission faithful to its original principles, preparing courses, doing research, advising students to become highly qualified professionals with critical though concerning their role in society."

The ranking of Brazilian Universities organized by the newspaper "Folha da São Paulo" distinguishes the UFABC as the Brazilian university more involved in international cooperation. The UFABCleads the rankin the item "Internationalization".

In May 2015 the prestigious British newspaper "The Guardian " published an article under the title: The Federal University of $A B C$ (UFABC).

The first paragraph reads:

"President Lula may have drwn much of his power base from the unions he represented in local industry, but in the creation of the $A B C$ region's Federal University he has paid back that loyalty. Shaking off the image of closed-off laboratories, conservative approaches and reluctance to change, UFABC is proving the shining example of what a public higher education in Brazil can become". 
This is a remarkable recognition of the high level that Brazilian higher education can reach. Unfortunately our the Brazilian media do not emphasize the histories of success, the disaster and misconduct have the priority.

Finally the recent choice of the São Bernardo do Campo county as the headquarters of the Swedish aircraft factory SAAB to produce fighters for the Brazilian Air Force has closed the overall purpose of the UFABC. The UFABC certainly played an important role in the SAAB's decision process. The unions that 10 years ago had a suspicious attitude towards the UFABC role in the industrial enhancement of the region are now asking for more investments on education and training for the region. Even the fostering of graduate courses in the region entered the list of the union demands.

\section{Figure 2: Evolution of the UFABC annual budget. The 2016 FY is estimated}

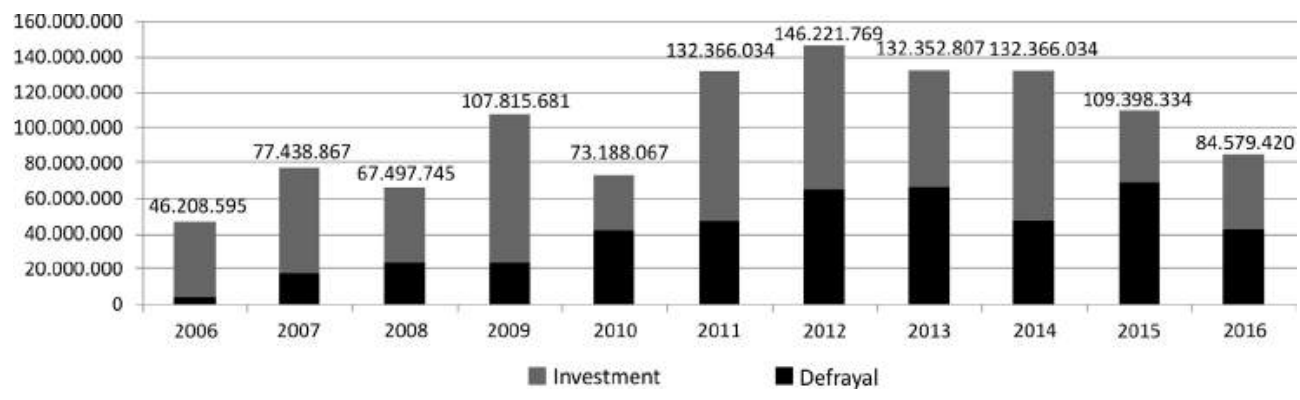

So it is very clear the extraordinary benefits that this new university with a revolutionary academic project, at least for the Brazilian standards, has brought not only for the local society but also for the national education system. In fact, after the success of UFABC other Brazilian universities are trying to reorganize their curricula to be more effective in the modern world. Now how to measure the impact on the economy brought by the quality of higher education is not an easy task. In any case, it is commonly accept all over the world that education plays a key role in the economic and industrial development. The public investment in higher education has been severely cut in the last two years. The figure 2 shows the recourses allocation to UFABC since its creation. It is imperative to recover the initial investment pace. The UFABC is now living a very productive cycle. Discontinuation will severely damage the scientific production and education for the future. With 562 professors, 12000 students 23 undergraduate courses and 23 graduate courses, with high academic evaluation and honored with more than 100 academic awards the UFABC is still in expansion phase particularly regarding laboratories and infrastructure. It would be a disaster to abandon such a singular initiative, which is bringing a renovation wave for the national higher education, with unquestionable success recognized internationally. 
We avoid introducing references. Complementary information can be obtained from the University homepage. Several dissertations have focused the UFABC project and evolution. We believe that a close follow up of the UFABC development will be extremely useful to analyze the factors that could influence the growth or the decay of a university in the Brazilian federal system. Finally it is important to mention that this August the number of graduate students in UFABC has reached the digit 1000. 


\section{A Short Report on Role of EMBRAPA in the Brazilian Agribusiness}

This section is a short account on the EMBRAPA role in the Brazilian agricultural complex. It is only to remind how worth is State investments. EMBRAPA's history and development trajectory has been well written by several authors [1] [2]. So it is not our purpose to summarize EMBRAPA's history but to show in brief numbers how important this Institution has been to the Brazilian economy and agricultural science and technology.

EMBRAPA, Brazilian Agricultura Research Corporation,a research section of the Ministry of Agriculture, Livestock and Food Supply was created in 1973 as the govenment's response to the challenge of modernizing agriculture to face the new and challenging problems of the modern world. This institution was given the mission of coordinating the Brazilian Agricultural Research System, integrating the actions of several Brazilian institutions involved with agricultural research. It was also within the EMBRAPA's scope to promote a more effective international cooperation.

Although EMBRAPA has been playing an excellent role in the development of the Brazilian industrial complex I would like to remind the contribution of a scientist who migrated to Brazil in the fifties and is an example for all our academic community: Dr. Johanna Döbereiner. Against the opinion of several well recognized scientists who sustained that working with bacteria to fix nitrogen was good only for theoretical purposes, with no practical application, she pursued her research and proved that she was right. Their opponents sustained that only the nitrogen fertilization could be effective to improve soybeans production. After strong discussions, involving Brazilian and mainly foreign scientists who were skeptical about her theory, she proved that she was right. This was possible with her breakthrough contribution showing that nitrogen fixation could be done introducing Azospirillum and other bacteria that could be useful to Brazilian soil following the discovery of nitrogen fixation bacteria in different species of vegetables, mainly grasses as corn and sugar cane. Dr. Döbereiner contribution is an extraordinary example of self-confidence, intellectual independence, courage to face new and challenging problems and passion for scientific research. Her discovery played a decisive role in EMBRAPA effort to adapt soybeans in the northeast of Brazil. Dr. Döbereiner proved that science is extremely useful to push technological development. It is important to say that investing in science has always been one of the most important of the EMBRAPA's priorities. In an interview for BBC Brazil, researchers in the field of agriculture were unanimous to declare that the most important contribution of EMBRAPA was the development of technologies that allowed for the correction of the soil acidity in the Northeast Brazil making possible the adaptation of plants 
coming from different biome. Before 1970 the Northeast region was irrelevant as a player in the agribusiness, nowadays this region contributes with almost $50 \%$ of the country's production.

- Among the main actions characterizing EMBAPA's priorities we may quote [2\}:

- The planning team includes people with economic and social sciences background that contribute decisively for the Institution's program. The Institution priorities are well defined and followed along the execution.

- The research is focused on the agribusiness as a whole. The purpose is to develop a system not a specific technology. The technology is part of the package.

- Departments were abolished and research units were created such that each unit could work out solutions more adequate to the requirements of the respective region.

It is also important to mention that EMBRAPA has an international outreach program.As stated in the EMBRAPA homepage the LABEX was created to " promote scientific and technological cooperation with other countries". To accomplish this target," Embrapa launched a program to set up virtual laboratories abroad, which seek to ensure Embrapa's physical presence outside of Brazil. The concept of virtual laboratoryentails sharing laboratory space and infrastructure with partner institutions."

EMBRAPA is a shining example that investing in technology is really worth it. As written in the Social Report 2014:

The Social Profit/Net Revenue ratio in 2014 was of 8.53. In order words, each Brazilian real invested was returned to Brazilian society multiplied by 8.53. The returns from Embrapa's investment in the 106 technologies monitored and assessed since 1997, the year of the Social Report's inception, also indicate high yield and an average internal rate of return (IRR) of $39.4 \%$.

In 2014, 66,255 new jobs were created. This is a baseline figure, as it refers to new jobs generated by the 106 technologies assessed in this report. Since Embrapa has developed and transferred thousands of technologies, products, and services to Brazilian society throughout the course of its history, such impact on the number of jobs created each year is certainly much higher.

The ongoing research is contributing continuously to the growth of the country. We may highlight the following initiatives as stated in the Social Report 2014: 
- Controle de Pesca do MatoGrosso do Sul -SCPesca/MS, which enabled the management and the conservation of fish stocks in Pantanal.

- Technology developed to reduce deforestation and to guarantee milk production in the Amazon region.

- App SuplementaCerto, a code which helps farmers decide on cattle feed during draughts.

- INPE-Embrapa Partnership in land monitoring in Amazonia extended to Cerrado.

- Booroola mutation program that expands sheep meat production in Southern Brazil.

- Draught-resistant cashew clone that generates wealth growth in Piauí semiarid.

- New gene bank that broadens Embrapa's contribution to food security in the planet.

- Embrapa's new website intended to increase the potential of technology transfer.

It is also important to mention that in 2014 EMBRAPA was distinguished with70 awards and honors. The growing contribution to scientific development is clear from figure 1.

Figure 1: Scientific publications in indexed journals according to Web of Science Period 1974 a 2013

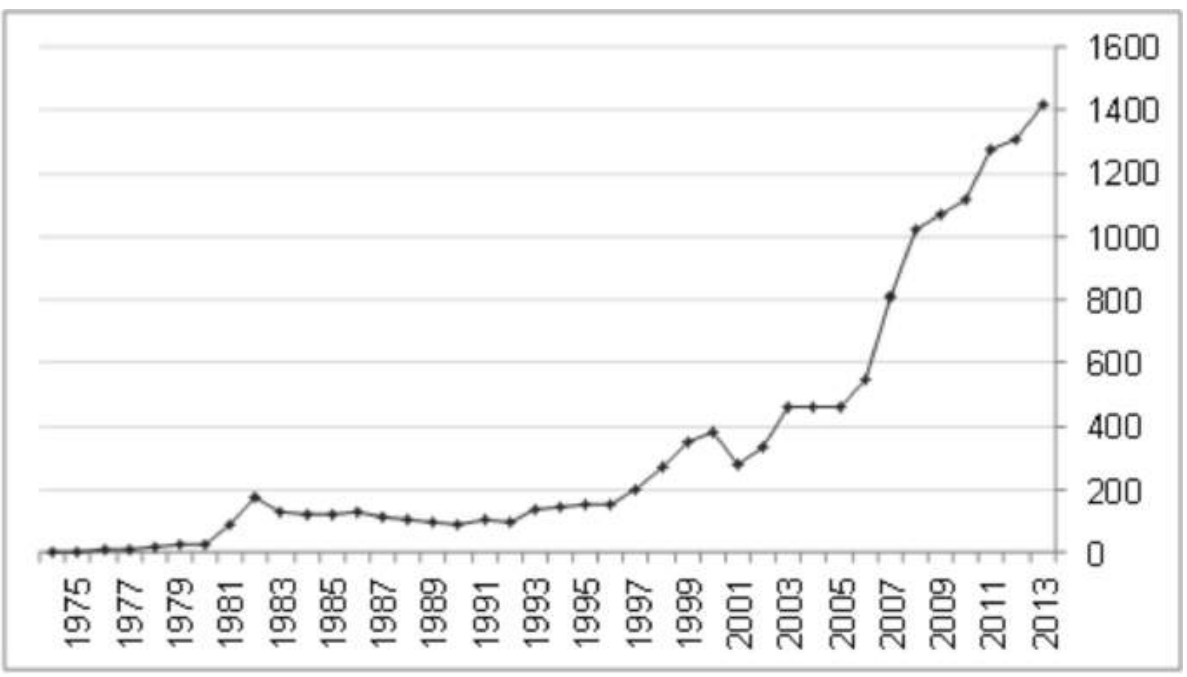

Among the new research topics the Amazon rain forest is attracting the attention of some of the researchers. The main focus is to invest in the adaptation of some 
species to be introduced in the region keeping inviolate the sustained environment requirements. This initiative could enhance the production of typical fruits of the Amazon region and push forward the exportation to other Brazilian regions and to other countries. It is also to mention some initiatives in the field of genetic improvement, which fall outside of the investment priorities of the private sector. If EMBRAPA is successful in these projects it can raise the institution to a competitive status with the private sector and reach very good position in the market provided that it can create a business sector.

Among the several contributions that EMBRAPA has brought to the national development we would like to highlight two points. The first concerns the extraordinary impact in the economy. Between 2002 and 2012 the exports by the Brazilian agribusiness sector was multiplied by seven. The contribution of the agribusiness export is essential to keep positive the Brazilian commercial balance. As seen from the figure 2 in 2012 the Brazilian exports coming from agribusiness activities reached 79.4 billion USD overcoming several times other activities and keeping positive the commercial balance exports-imports.

Figure 2: Trade balance and contribution of the agribusiness

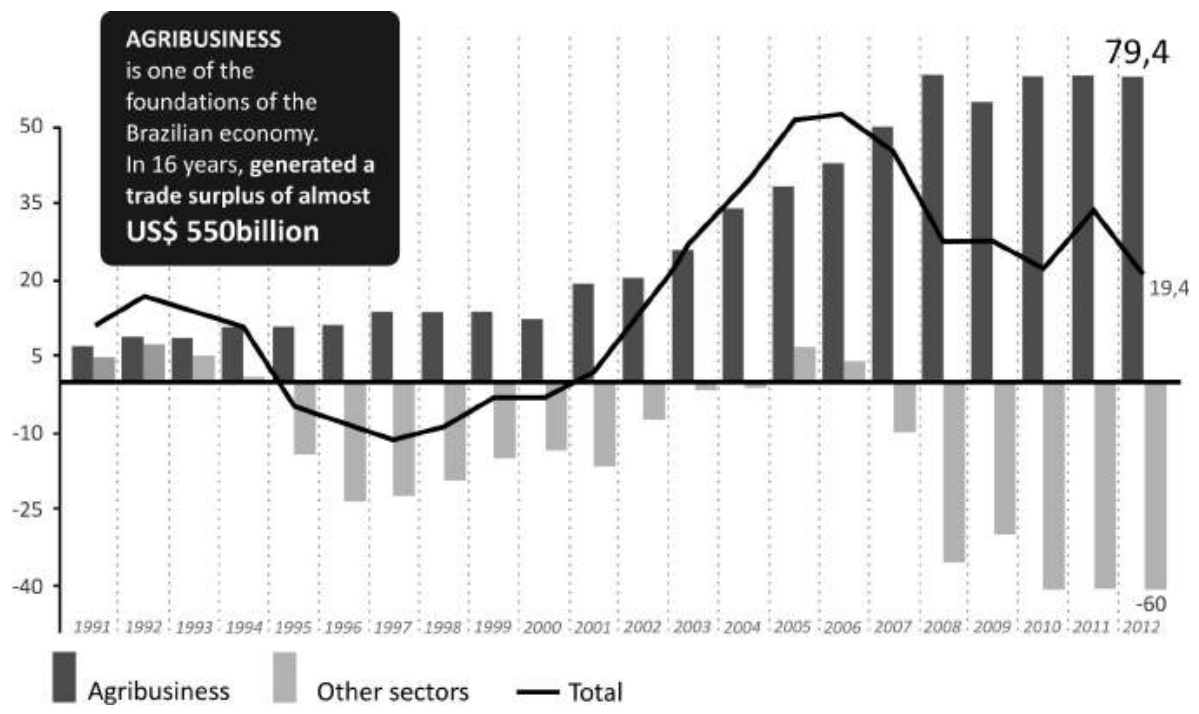

Source: Agrostat (MAPA)

The second point refers to the contribution of EMBRAPA to the increase of the Brazilian agricultural and cattle production. It is impressive as can be seen from the figure 3. Particularly remarkable is the increase in the soybeans production reaching the level of almost ten thousand percent in the period 1965/2005. 
Figure 3: Performance of the Brazilian agribusiness 1965-2005 in tons

\begin{tabular}{|l|r|r|r|r|r|r|}
\hline Ano & \multicolumn{1}{|c|}{1965} & \multicolumn{1}{c|}{1975} & \multicolumn{1}{c|}{1985} & \multicolumn{1}{c|}{1995} & \multicolumn{1}{c|}{$\mathbf{2 0 0 5}$} & \multicolumn{1}{c|}{$\begin{array}{l}\text { Var.\% } \\
\mathbf{1 9 6 5 / 2 0 0 5}\end{array}$} \\
\hline Cana-de-açúcar & 75.852 .864 & 91.524 .560 & 247.199 .472 & 303.699 .488 & 420.120 .992 & 453,9 \\
Soja em grão & 523.176 & 9.893 .008 & 18.278 .592 & 25.682 .636 & 52.700 .000 & $9.973,1$ \\
Milho em grão & 12.111 .921 & 16.334 .516 & 22.018 .176 & 36.266 .952 & 34.859 .600 & 187,8 \\
Laranja & 2.285 .524 & 6.313 .171 & 14.214 .307 & 19.837 .212 & 17.804 .600 & 679,0 \\
Arroz & 7.579 .649 & 7.781 .538 & 9.024 .555 & 11.226 .064 & 13.140 .900 & 73,4 \\
Fumo & 248.182 & 285.934 & 410.474 & 455.986 & 878.651 & 254,0 \\
Trigo & 585.384 & 1.788 .180 & 4.320 .267 & 1.533 .871 & 5.200 .840 & 788,4 \\
Feijão & 2.289 .796 & 2.282 .466 & 2.548 .738 & 2.946 .168 & 3.076 .010 & 34,3 \\
Carnes Total & 2.420 .782 & 3.589 .592 & 5.898 .738 & 12.807 .517 & 19.919 .135 & 722,8 \\
Leite (mil litros) & 6.857 .813 & 10.054 .500 & 12.572 .830 & 17.126 .100 & 23.455 .000 & 242,0 \\
\hline
\end{tabular}

In a recent report [4] the following guidelines were proposed to steer EMBRAPA's research effort. The following themes were selected following the input of the production chains that allowed the identification of the most important technological challenges in the several agribusiness activities. The selected topics are:

- Natural resources and climate changes

- New science: biotechnology, nanotechnology and geotechnology

- Automation, information technology, and precision agriculture

- Sanitary safety of agricultural products and productive chains

- Production systems

- Agro-industrial technologies of biomass and green chemistry

- Safety measures for food, nutrition and health.

- Markets, policies and rural development

Finally, we would like to call the attention about the evolution of EMBRAPA's budget in the last 15 years [4]. After a critical phase encompassing the period 1995- 2003 when the institution budget decreased drastically from $1.38 \%$ to $0.73 \%$ of the gross domestic product (GDP) of the agribusiness sector there was a partial recovery to reach the level of approximately $1,0 \%$ of the agribusiness GDP (Fig. 4).

Figure 5 displays the institution budget in the last 15 years. Recently there was an increase in the amount allocated to EMBRAPA by the Federal Government. It is clear that this institution deserves the maximum support from governmental investment agents. The return of the investments to compensate the imbalance of the exportimport relation justifies this policy. It is very important to sustain the effectiveness of institutions like EMBRAPA in the middle of temporary turmoil affecting the 
national and global economies. We believe that it is one of the most important activities of the economic authority to define priorities in difficulty times. EMBRAPA has proved to bring unique contribution to Brazilian economy, agricultural science and agribusiness, it must be preserved.

Figure 4: Evolution of EMBRAPA's budget as a fraction of the gross domestic product corresponding to the agribusiness activities

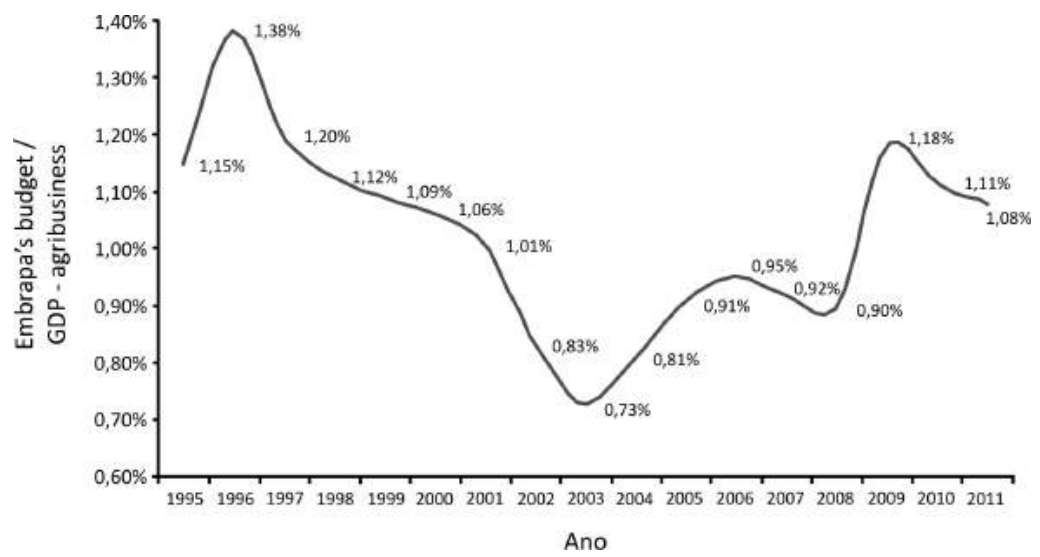

Figure 5: Evolution of EMBRAPA's budget in R\$ billions

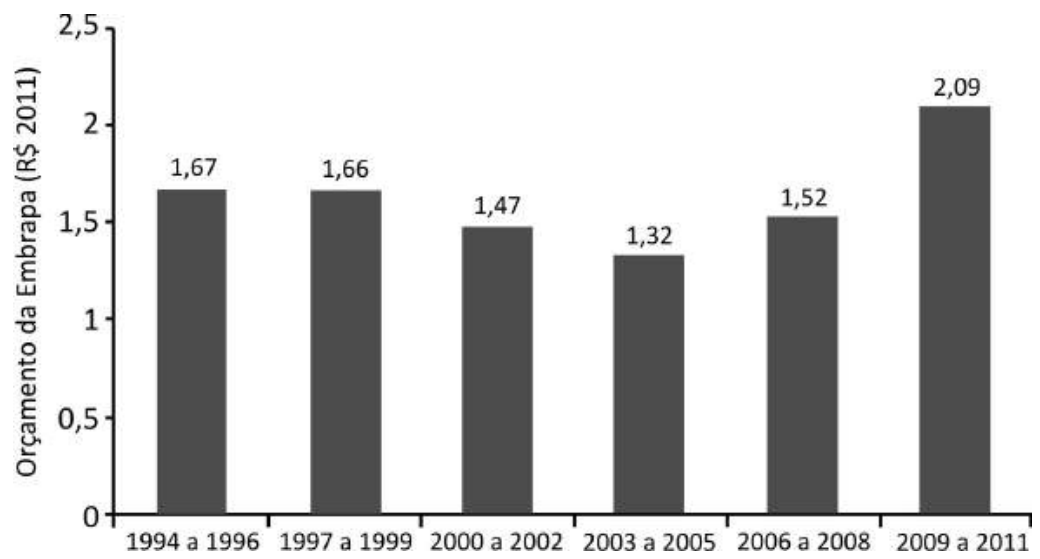

This was a very short account on the EMBRAPA's role in the Brazilian agribusiness industry. There are several papers and books on EMBRAPA's history and role in Brazilian economy that the reader could easily access. The main conclusion is that public investment is worth, provided that, the people involved are competent and able to think independently, the problems are challenging, and the targets are well defined. EMBRAPA is one of these. 


\section{References}

[1] Geraldo B. Martha JR., Elisio Contini, Eliseu Alves, The Regional Impact of National Policies: The case of Brazil ;Edited by Werner Baer, Elgaronline, (2012) DOI:10.4337/9780857936707.00016

[2] Alex Alexandre Mengel, Modernização da Agricultura e Pesquisa no Brasil: A Empresa Brasileira de Pesquisa Agropecuária,Embrapa. Tese de Doutorado, UFRRJ, 2015

[3] SIDEMAR PRESOTTO NUNES, O desenvolvimento da agricultura brasileira e mundial e a idéia de Desenvolvimento Rural. Departamento de Estudos Socio-Econômicos Rurais,Boletim Eletrônico, Conjuntura Agricola, no 157, março 2007.

[4] EMBRAPA - Visão 2014-2034 O futuro do desenvolvimento tecnológico da agricultura brasileira, Brasília, EMBRAPA 2014.

Luiz Bevilacqua

Emeritus Professor at Alberto Coimbra Institute, COPPE/UFRJ, Brazil.

Contact: bevilacqua@coc.ufrj.br 